\title{
TRANSFORMATION OF COPING IN THE SOCIAL SITUATION OF TRANSITIVITY: CROSS-CULTURAL ASPECT
}

\author{
Vasilisa Orestova $^{1}$, Dmitry Khoroshilov ${ }^{1}$, \& Elena Belinskaya ${ }^{2}$ \\ ${ }^{1}$ Russian State University for the Humanities (Russia) \\ ${ }^{2}$ Russian State University for the Humanities, Moscow State Lomonosov University (Russia)
}

\begin{abstract}
In the modern world, when the situation of social transitivity is, in fact, a complex difficult situation, it is relevant to turn to the study of coping methods that are characteristic and specific to this situation. A special role in the study of coping in a transitive society can be played by turning to cross-cultural studies that allow us to trace the transformations of coping in the context of modernization society.

The article presents the results of a thematic analysis of narratives and free-form interviews of respondents from Russia and Uzbekistan, which allow us to conclude that the transformation of coping strategies in the process of modernizing traditional culture goes along the path of individualization, which is expressed as the need to take individual responsibility for solving difficult situations, and in the formation of a flexible repertoire of coping strategies that correspond to an individualistic, rather than a receding traditional collectivist culture. The study allows not only to understand individual strategies of perception, categorization and affective assessment of difficult life situations by representatives of different cultures, but also makes it possible to interpret them in the broader context of studying coping processes in a situation of social uncertainty and variability.
\end{abstract}

Keywords: Transitivity, modernization, coping, culture.

\section{Introduction}

Today, when the transitivity of the socio-cultural space, characterized by uncertainty and variability of its parameters, is, in fact, a kind of difficult life situation for a person (Martsinkovskaya, 2015), the study of coping methods characteristic of this situation becomes particularly relevant. The socialization of a modern person takes place in an information space characterized by uncertainty, multiplicity, and variability of its parameters, and to some extent, this is typical even for people living in fairly traditional culture. In an ever-changing world, there is an expansion of the range of problematic situations and the absence of effective ways to overcome them formed in the traditional culture, which requires a review of the old and the development of new coping strategies. The appeal to qualitative cultural and cross-cultural studies (Swartz, Rohleder, 2017) allows us to reveal the question of how the transformation of coping strategies occurs in the process of modernization of traditional culture, which is inevitable in a situation of socio-cultural transitivity in post-soviet states (Kivinen, Humphreys, 2021).

Coping behavior is a function of the person in the environment. The concept of the interaction of personality and situation goes back to the classical ideas of K. Lewin and is today, perhaps, one of the most popular approaches in both personality psychology and social psychology (Lewin, 2017). It is assumed that in the context of the study of coping, a similar model can be used, where coping behavior is considered as a function of the subjective interpretation of the situation and is modified by its real requirements. Various cognitive, motivational, and emotional factors that determine coping behavior can be correlated with a person's categorization of the psychological meaning of the situation.

The theoretical and empirical analysis of the problem of coping from the standpoint of the situational approach requires taking into account a variety of contextual variables, among which the cultural environment of a person is the most important one. A separate direction is related to the study of coping behavior in traditional cultures as a function of the rituals of transition and initiation, which is the disciplinary heritage of anthropology and ethnography. The main difficulty of the situational approach lies in the fact that the tools available to psychologists are not able to record the dynamic change in the personality - situation relationship. The qualitative analysis of coping strategies with the dynamic cultural changes in modern societies can partially solve this problem. 
In psychology, quantitative methods are used to study the cultural determination of coping behavior; the relevant tools are clearly developed and validated, and the rich empirical is the subject of the meta-analysis and interdisciplinary interpretation (Belinskaya, 2009; Carver, Connor-Smith, 2010). In recent years the Russian psychologists use projective methods and qualitative content analysis of respondents' self-reports for the study of coping behavior (Bityutskaya, Kartseva 2013).

\section{Research design and methods}

The objective of cross-cultural qualitative research was to study the experience of difficult life situations and coping strategies in Russia and Uzbekistan. The purposive sample included the students $(n=60)$ of universities in Tashkent $(n=30)$ and Moscow $(n=30)$ aged 18 to 21. Respondents shared their experience of difficult life situations in unstructured narrative interviews. The original question was what they consider as a difficult life situation, what examples from the everyday life they can remember, and finally how they tried to cope with it. All materials were analyzed with the method of thematic analysis. The main strategies of thematic analysis are as follows: 1. familiarizing yourself with your data; 2. generating initial codes; 3. searching for themes; 4. reviewing themes; 5. defining and naming themes; 6. producing the report (Braun, Clarke, 2006).

\section{Results and discussion}

Thematic analysis of narratives reveals similar perceptions by respondents from Moscow and Tashkent of problematic or difficult situations in everyday life. These include illness and death of the old relatives and young friends, interpersonal conflicts, making life-changing decisions, learning difficulties. Although the listed topics are invariant for the two purposive samples, there is a cross-cultural difference in their interpretation, which concerns the degree of individualization of coping strategies and the dynamics of the Self - Other relationship in conflict situations of interpersonal communication.

It became obvious at the stage of data collection that respondents from Tashkent are franker in describing personal and sometimes traumatic experiences than respondents from Moscow.

The narratives of respondents from Tashkent about the experience of the loss of close relatives are distinguished by genuine drama (the death of a grandfather as an elder of the family or the death of a parent of the opposite sex is often mentioned). The respondents are focused on supporting a significant Other than on independent internal "working through" the traumatic experience. The psychological work of grief and melancholy are projected onto the suitable authority figures of parents who, contrary to their expectations, confine themselves to formal and traditional prescriptions, as reflected in the following passage: "Several years ago, when I lost my grandfather, I could not stop crying, all the while thinking about what I had not done with him. He often repeated the date of his possible death, and then I blamed myself for not believing his words. It was just a storm of despair. Mom said: because I cry, it is not easier for him, my tears, according to Islam, keep him in this world. I decided to look after his grave and pray for him. I collected in the form of a photo album all the moments when we were together. She thanked him for the love for me, which she could not make up for him, but simply did not have time".

The second theme with a characteristic heightened emotional resonance in the narratives of the respondents from Tashkent is acute interpersonal conflicts, in which personal and intergroup boundaries are often violated between different generations, family clans, and social classes. The most common plot is associated with parental interference in romantic relationships ("My parents read my correspondence with my boyfriend without my knowledge"; "I loved the young man, and he reciprocated until he met his mother, who rejected me because of the finances of my family and my appearance, and he abandoned $m e$ "). Parents also participate in interpersonal conflicts of their children ("Betrayal of a friend: she set me up, she talked to the guys on social networks, and told her mother that it was me. Her mother called my mother and said that I was ill-mannered. My illusions about our friendship scattered"). A friend can be replaced by an animal, which only increases the emotional tension of the encounter with his loss ("I had a dog, my parents gave it away without my knowledge after 3 years of life. There was such an insult and emptiness, I sat in the room for three days, did not talk to anyone, watched films about dogs and cried even more"). The topic of relationships with parents appears in these narratives as relationships mainly with a parent of the same sex, who acts both as a source of normative prescriptions regarding models of social behavior, and as an object of negative feelings (resentment, anger).

Nothing of the kind was found in the narratives of respondents from Moscow: their various spheres of life and relationships are quite clearly differentiated, and interpersonal conflicts were resolved constructively or were forgotten and displaced. In other words, they demonstrated a versatile and flexible repertoire of coping strategies in various situations, more focused on reflection and analysis than on immersion in long-term worries about the difficulties that have arisen. 
The two designated themes are related to each other: the real loss of a significant Other becomes a symbolic indication of the lack of cultural and psychological resources for independent coping with difficult situations concerning tangled interpersonal (and intergenerational) relationships. Because of this circumstance, the respondents from Tashkent have to "invent" coping strategies in everyday life (because the hopes for support and care of the family circle are dashed against the traditional social prescriptions of its members). Here are several illustrations: "Nobody knew the reasons, I read, listened to music", "I grieved, watched TV shows and drank sleeping pills", "I told myself in my mind: I am a psychologist, and I can make everything so good." It is characteristic that indications of consistently pronouncing for themselves the chosen coping strategies (regardless of the sphere of life where they arose) are found only in the Tashkent sample.

\section{Conclusions}

The narrative experience of coping in post-soviet societies can be interpreted as a psychological reflection of the modernization of the traditional culture and the transformation of its collectivist attitudes into individualistic ones. According to K. Girtz, modernization transforms a traditional form of life, stable and closed, into a risky form of life, adapting and constantly changing (Geertz, 1995). A significant expansion of the range of problematic and difficult situations in a transitive societies requires taking individual responsibility for their decisions and the formation of a flexible repertoire of coping strategies that correspond to individualistic rather than traditional collectivist culture (what becomes evident in the cross-cultural perspective).

\section{Acknowledgments}

This work was supported by the Russian Science Foundation, project 19-18-00516 "Transitive and virtual spaces - commonality and differences".

\section{References}

Belinskaya, E.P. (2009), “Coping as social-cultural problem”. Psikhologicheskie Issledovaniya, 1 (3), [In Russian, abstract in English] Retrieved from http://psystudy.ru (Accessed 9 Dec 2020).

Bityutskaya, E.V. \& Kartseva, E.V. (2013). ""My difficult life situation" drawing technique as a diagnostic tool of perception of a difficult situation". Journal of Practical Psychologist, no. 4, pp. 102-132.

Braun V.\& Clarke V. (2006). Using thematic analysis in psychology. Qualitative Research in Psychology, Vol. 3, p. 77-101.

Carver, C.S. \& Connor-Smith, J. (2010), "Personality and coping”. Annual Review of Psychology, vol. 61, pp. 679-704.

Geertz C. (1995). After the Fact: Two Countries, Four Decades, One Anthropologist. Cambridge, Mass.: Harvard University Press.

Kivinen M. \& Humphreys B. (Eds.). (2021). Russian Modernization: A New Paradigm. L.: Routledge.

Lewin K. A (2017) Field theory in social sciences. M.: Akademicheskij proekt

Martsinkovskaya, T.D. (2015). Modern psychology - challenges of transitivity. Psikhologicheskie Issledovaniya, 8(42), 1. [In Russian, abstract in English] Retrieved from http://psystudy.ru/index.php/num/2015v8n42/1168- martsinkovskaya42.html

Swartz L. \& Rohleder P. (2017) Cultural Psychology. Ed. by C. Willig \& W. Stainton-Rogers. The Sage handbook of qualitative research in psychology (P. 561-571). L.: Sage. 